\title{
Lobar Lung Resection in Elderly Patients With Non-Small Cell Lung Carcinoma: Impact of Chronic Obstructive Pulmonary Disease on Surgical Outcome
}

\author{
O. Senbaklavaci
}

Department of Cardiothoracic and Vascular Surgery, Johannes Gutenberg University, Mainz, Germany

The aim of this study was to evaluate the impact of chronic obstructive pulmonary disease (COPD) on the perioperative morbidity and mortality after lobar lung resection for non-small cell lung cancer (NSCLC) in patients aged 70 years and older. The medical records of 73 patients $\geq 70$ years who underwent lobar lung resection for NSCLC from 2003 to 2013 at our department were reviewed retrospectively. There were 27 patients with a mean age of 73.6 years and mean predicted forced expiratory volume in $1 \mathrm{~s}$ (FEV1) of $69.7 \%$ in the COPD group whereas remaining 46 patients (mean age $=75.6$ years) in the non-COPD group had a mean predicted FEV1 of $79.1 \%$. There were no significant differences in perioperative morbidity $(4.8 \%$ in the COPD group versus $17.4 \%$ in the nonCOPD group) between both groups. We had no perioperative mortality in both groups. Lobar lung resection for NSCLC seems to be a safe therapy option for elderly patients with COPD who are fulfilling the common functional criteria of operability so that radical surgery should remain the mainstay of treatment for early-stage NSCLC in this increasing subpopulation.

Key words: Non-small cell lung carcinoma - Elderly - Lung resections - Chronic obstructive pulmonary disease

W

hile NSCLC is the leading cause of malignancy-related mortality in western countries, ${ }^{1}$ COPD was reported to be the fifth leading cause of death worldwide in 2005, according to the World Health Organization (WHO). ${ }^{2}$ Actually about 80 million people are suffering from COPD in the

Corresponding author: O. Senbaklavaci, Department of Cardiothoracic and Vascular Surgery, Johannes Gutenberg University, Mainz, Langenbeckstr. 1, 55131 Mainz, Germany.

Tel.: +49 163 7854872; Fax: +49 613117 5513; E-mail: senbak@hotmail.com 
Table 1 Patient characteristics and preoperative comorbidities

\begin{tabular}{lccc}
\hline Variable & COPD $(\mathrm{n}=27)$ & Non-COPD $(\mathrm{n}=46)$ & P-value \\
\hline Female $(\mathrm{n})$ & 23 & 33 & $\mathrm{NS}$ \\
Mean age (range) & $73.6(70-80)$ & $75.6(70-84)$ & 0.03 \\
Mean FeV $(\%) \pm \mathrm{SD}$ & $69.7 \pm 10.3$ & $75.6 \pm 4.1$ & 11 \\
Ischaemic heart disease & 8 & 22 & $\mathrm{~N}$ \\
Arterial hypertension & 12 & 14 & $\mathrm{NS}$ \\
Diabetes mellitus & 7 & 5 & $\mathrm{NS}$ \\
Abdominal aortic aneurysm & 3 & 28 & $\mathrm{NS}$ \\
Previous other malignomas & 5 & 0.0006 \\
\hline
\end{tabular}

$\mathrm{SD}$, standard deviation; NS, not significant; $\mathrm{FeV}_{1}$, forced expiratory volume in $1 \mathrm{~s}$.

world and due to its rising incidence it is expected to be the third leading cause of death worldwide by $2020 .^{3,4}$ Incidence of both diseases diagnosed in the elderly people is rising due to increasing life expectancy. Demographic projections from the Federal Statistical Office of Germany indicate that by the year 2050 the number of citizens over 70 years will increase to $26.6 \%$ of the total population in Germany. ${ }^{5}$ It is generally accepted that elderly patients with non-small cell lung cancer (NSCLC) should not be excluded from curative resection only due to their chronological age as the operative results in this group are similar to that of younger patients. ${ }^{6-11}$ The negative impact of COPD after pulmonary resections for NSCLC has been discussed in several studies, but the following question still remains to be answered: How fit are elderly patients with COPD for lobar lung resection ${ }^{12-19}$

The aim of this study was to evaluate the impact of COPD on operative morbidity and mortality in patients aged 70 years or older with NSCLC undergoing lobar lung resection.

\section{Materials and Methods}

We retrospectively reviewed 73 patients aged 70 years or older with NSCLC who underwent lobectomy and bilobectomy between 2003 and 2013 at our institution. Patients were divided into COPD and non-COPD groups, defined as a ratio of FEV1/forced vital capacity (FVC) $<0.7$ or a ratio of $\geq 0.7$, respectively. Twenty-seven patients with a mean age of 73.6 years were in the COPD group whereas remaining 46 patients (mean age $=75.6$ years) were categorized as the non-COPD group. Analyzed demographic and clinical variables included age, gender, pulmonary function, and concomitant diseases.

All patients met the standard cardiopulmonary criteria for elective surgery. Due to the guidelines of the American College of Chest Physicians, only patients with an estimated postoperative FEV1 > $40 \%$ predicted were accepted for surgery. ${ }^{20}$ Patients in the COPD group have been operated after optimization of their antiobstructive therapy. Operations were performed under general anesthesia through lateral thoracotomy completed with hilar and mediastinal lymphadenectomy.

Pulmonary resections included lobectomy and bilobectomy whereas patients with segmentectomy, wedge resection, and pneumonectomy were excluded. Staging was re-evaluated according to the seventh edition of the TNM classification. ${ }^{21}$ Histologic typing was carried out according to the World Health Organization histologic classification. ${ }^{22}$

Morbidity was defined as any postoperative event, such as pneumonia, major bleeding requiring reoperation, prolonged air leak with postoperative chest tube drainage $>7$ days, wound infection, or pleural effusion requiring renewed drainage. Operative mortality was defined as death within 30 days after the operation.

Statistical analysis was performed using Fisher's exact test for categoric data and $t$ test for continuous data. A two-tailed $P$-value of $<0.05$ was considered to be statistically significant.

\section{Results}

\section{Demographics and clinical data}

The details of patients' preoperative characteristics are shown in Table 1. Patients in the non-COPD group were significantly older than patients in the COPD group. Patients in the COPD group had, as expected, significantly lower FEV1, whereas patients in the non-COPD group showed more previous other malignomas in their histories. Remaining comorbidities were comparable in both groups. 
Table 2 Type of pulmonary resection

\begin{tabular}{lccc}
\hline $\begin{array}{l}\text { Pulmonary } \\
\text { resection }\end{array}$ & $\begin{array}{c}\text { COPD } \\
(\mathrm{n}=27)\end{array}$ & $\begin{array}{c}\text { Non-COPD } \\
(\mathrm{n}=46)\end{array}$ & $P$-value \\
\hline $\begin{array}{l}\text { Lobectomy } \\
\text { Bilobectomy }\end{array}$ & 27 & 39 & 0.04 \\
\hline
\end{tabular}

\section{Surgical data}

The operative procedures are listed in Table 2. There were significantly more bilobectomies in the nonCOPD group.

\section{Histology and staging}

Analyses of histologic findings (Table 3) and clinical stages (Table 4) showed no significant differences between both groups.

\section{Operative morbidity and mortality}

All patients were extubated in the operating room. Mean length of hospital stay in COPD group was 10.7 days and in non-COPD group 11.1 days $(P=$ NS). There were also no significant differences in operative morbidity between two groups (Table 5). There was no mortality in both groups.

\section{Discussion}

Our data support that lobar lung resections for NSCLC can be performed safely in elderly patients with COPD who are fulfilling the common functional criteria of operability.

Lung cancer and COPD are common fatal diseases with dramatic economic and social burdens worldwide. ${ }^{23-25}$ NSCLC is actually the leading cause of malignancy-related mortality in western countries. ${ }^{1}$ In 2011, there were 43.908 deaths due to NSCLC in Germany, according to $5.2 \%$ of all deaths and causing the most malignancy-related deaths in the country. ${ }^{26}$ Actually about 80 million people are suffering from COPD in the world and due to its rising incidence it is expected to be the third leading

Table 3 Histologic findings

\begin{tabular}{lccc}
\hline Histology & $\begin{array}{c}\text { COPD } \\
(\mathrm{n}=27)\end{array}$ & $\begin{array}{c}\text { Non-COPD } \\
(\mathrm{n}=46)\end{array}$ & $P$-value \\
\hline Adenocarcinoma & 3 & 6 & NS \\
Squamous cell carcinoma & 24 & 38 & NS \\
Adenosquamous cell carcinoma & 0 & 2 & NS \\
\hline
\end{tabular}

NS, not significant.
Table 4 Clinical stages

\begin{tabular}{lccc}
\hline Stage & $\begin{array}{c}\text { COPD } \\
(\mathrm{n}=27)\end{array}$ & $\begin{array}{c}\text { Non-COPD } \\
(\mathrm{n}=46)\end{array}$ & $P$-value \\
\hline I A + I B & 15 & 26 & NS \\
II A + II B & 9 & 16 & NS \\
III A & 3 & 7 & NS \\
\hline \multicolumn{2}{c}{ NS, not significant. } & &
\end{tabular}

cause of death worldwide by $2020 .^{3,4}$ It was responsible for 26.018 deaths in Germany in 2011, according to fifth leading cause of death. ${ }^{26}$ The BOLD-study (Burden of Obstructive Lung Disease) reported that the prevalence of this disease is about $13.2 \%$ in Germany. ${ }^{3}$ The association between COPD and NSCLC has been reported in several studies. Reports have shown that $50-80 \%$ of patients with NSCLC had pre-existing COPD. ${ }^{27,28}$ On the other hand, the risk of lung cancer in patients with COPD is two- to fivefold greater compared with smokers without COPD. ${ }^{29-31}$ Possible mechanisms for this association seem to be the chronic inflammation associated with COPD and a shared genetic susceptibility. ${ }^{14}$ Chronic inflammation is known to cause malignant transformation also in other organs. ${ }^{32-34}$ Demographic projections from Federal Statistical Office of Germany indicate that by the year 2050 the number of citizens over 70 years will increase to $26.6 \%$ of the total population in Germany. ${ }^{5}$ Due to expected similar trend in Western countries, elderly patients presenting NSCLC and COPD coincidentally, will also be increasing markedly and the surgical therapy of these patients is challenging and not yet clearly defined.

On one hand it is generally accepted that elderly patients with NSCLC should not be excluded from curative resection only due to their chronological age as the operative results in this group are similar to younger patients. ${ }^{6-11}$ On the other hand the negative impact of COPD after pulmonary resec-

Table 5 Perioperative events

\begin{tabular}{|c|c|c|c|}
\hline Variable & $\begin{array}{c}\text { COPD } \\
(\mathrm{n}=27)\end{array}$ & $\begin{array}{c}\text { non-COPD } \\
(\mathrm{n}=46)\end{array}$ & $P$-value \\
\hline Overall morbidity (\%) & 14.8 & 17.4 & NS \\
\hline Pneumonia & 3 & 3 & NS \\
\hline Prolonged air leak & 0 & 1 & NS \\
\hline Pleural effusion & 0 & 1 & NS \\
\hline Re-operation due to bleeding & 0 & 2 & NS \\
\hline Wound infection & 0 & 1 & NS \\
\hline 30-day mortality & 0 & 0 & NS \\
\hline
\end{tabular}


tions for NSCLC has been discussed in several studies, ${ }^{12-19}$ but the following question still remains to be answered: Can lobar lung resection, recently the mainstay of treatment for early-stage NSCLC, be offered to elderly patients with NSCLC and COPD without any adverse impact on postoperative outcome? In our retrospective analysis we could answer this question with yes.

The British Thoracic Society, in its guidelines on the selection of patients for lung cancer surgery, recommends that all patients should have equal access to lung cancer services regardless of age. ${ }^{35}$ In a large retrospective study with 1073 patients, Takamochi et al reported that the rate of morbidity and mortality after pulmonary resection in elderly patients were similar to those observed in younger patients. ${ }^{9}$ Another large retrospective study with 1114 patients, reported by Sawada et al, confirmed that, in elderly patients, the rate of perioperative mortality and the prognosis after pulmonary resections were also similar to those in the younger patients. ${ }^{36}$ Gray et al identified a national cohort of 17,638 Medicare patients aged $\geq 66$ years living in Surveillance, Epidemiology, and End Results (SEER) areas who were diagnosed with stage I or II NSCLC. Areas with high and low rates of curative surgery for early stage lung cancer were compared to estimate the effectiveness of surgery in older and sicker patients. ${ }^{7}$ The authors concluded that higher rates of surgery for stage I/II NSCLC were associated with improved survival, even when older patients and sicker patients underwent resection.

In contrast to advanced age, COPD is accepted to be a limiting factor for pulmonary resections in patients with NSCLC. In a large retrospective study with 1461 patients who underwent pulmonary resection for lung cancer, Sekine et al divided the patients into 4 groups according to spirometric guidelines of GOLD: non-COPD, mild COPD, moderate COPD, and severe COPD groups, and analyzed not only perioperative complications and mortality but also long-term survivals. ${ }^{12}$ The authors reported that the frequencies of all pulmonary complications in 3 COPD groups were higher than in the nonCOPD group and concluded that higher COPD grades had higher rates of postoperative pulmonary complications and poorer long-term survivals because of higher rates of cancer-related deaths.

In another retrospective study on 1239 patients, Licker et al reported that preoperative FEV1 less than $60 \%$ was a main predictor of perioperative mortality and respiratory morbidity after lung cancer resection. ${ }^{15}$
Nonetheless it is generally recommended that every lung cancer patient with COPD should be routinely evaluated with intention of curative surgical resection as actual available data suggest that limited resections should be avoided in patients who can tolerate lobectomy. ${ }^{14,19,37}$ In patients with a preoperative FEV1 or carbon monoxide diffusing capacity (DLCO) of $<80 \%$ predicted, the predicted postoperative lung function should be calculated to estimate the safety and feasibility of resection. While quantitative CT scans or anatomic estimation are efficient methods prior to lobectomies, ventilation/ perfusion scans are recommended before pneumonectomies. Generally, a predicted postoperative value for FEV1 or DLCO greater than $40 \%$ has been suggested as a safe cutoff. ${ }^{20}$ In our experience, patients with a predicted postoperative FEV1 $<40 \%$ either received a limited resection or were rejected for surgical treatment thus having been excluded from this study. Six-minute walk tests and cardiopulmonary exercise testing can further provide information to help surgeons estimate perioperative risk. $^{14}$

To our knowledge, the impact of COPD on postoperative outcome after lobar lung resection in lung cancer patients aged 70 years or older has not yet been described in the literature. In contrast to the literature, we observed no significant difference in postoperative morbidity between both groups. This could be explained on one hand with the fact we had only patients with mild and moderate COPD in the study group who were significantly younger and had significantly less previous other malignomas than patients in the non-COPD group, indicating good preoperative physical status. Patients in COPD group received on the other hand significantly less bilobectomies than patients in the nonCOPD group. To our surprise we observed no prolonged air leak in COPD group. Although not significant, patients in the COPD group had higher incidence of postoperative pneumonia $(11.1 \%)$ than patients in the non-COPD group $(6.5 \%)$, which is concordant with the literature. We believe that preoperative optimization of the antiobstructive therapy and preoperative pulmonary rehabilitation play a key role in the surgical treatment of this challenging patient subset.

\section{Study limitations}

The main limitation of our study is its retrospective nature as a single-institution study with a small sample size. Its findings should only be restricted to 
patients with mild and moderate COPD as we had no patients with severe COPD in our study group. Furthermore we defined COPD by functional limitation only without considering further criteria like DLCO, radiologic findings and clinical criteria which could limit the reproducibility of our results. So our findings need to be confirmed in large, prospective randomized multicenter trials.

\section{Conclusion}

In our experience, lobar lung resections for NSCLC seem to be a safe therapy option for elderly patients with COPD who are fulfilling the common functional criteria of operability.

\section{References}

1. Suemitsu R, Takeo S, Hamatake M, Yoshino J, Motoyama M, Tanaka $\mathrm{H}$. The perioperative complications for elderly patients with lung cancer associated with a pulmonary resection under general anesthesia. J Thorac Oncol 2009;4(2):193-197

2. World Health Organization. Chronic obstructive pulmonary disease (COPD). Fact sheet No. 315, 2012. Available at http:/ / www.who.int/mediacentre/factsheets/fs315/en/index.html. Accessed May 1, 2014.

3. Geldmacher H, Biller H, Herbst A, Urbanski K, Allison M, Buist AS et al. The prevalence of chronic obstructive pulmonary disease (COPD) in Germany. Results of the BOLD study. Dtsch Med Wochenschr 2008;133(50):2609-2614

4. Murray CJ, Lopez AD. Alternative projections of mortality and disability by cause 1990-2020: Global Burden of Disease Study. Lancet 1997;349(9064):1498-1504

5. Federal Statistical Office of Germany. https://www. destatisde.de/EN/FactsFigures/SocietyState/Population/ PopulationProjection/PopulationProjection.html

6. Liu HC, Huang WC, Wu CL, Huang JT, Chen CH, Chen YJ. Surgery for elderly lung cancer. Ann Thorac Cardiovasc Surg 2013;19(6):416-422

7. Gray SW, Landrum MB, Lamont EB, McNeil BJ, Jaklitsch MT, Keating NL. Improved outcomes associated with higher surgery rates for older patients with early stage nonsmall cell lung cancer. Cancer 2012;118(5):1404-1411

8. Booton R, Jones M, Thatcher N. Lung cancer.7: Management of lung cancer in elderly patients. Thorax 2003;58(8):711-720

9. Takamochi K, Oh S, Matsuoka J, Suzuki K. Risk factors for morbidity after pulmonary resection for lung cancer in younger and elderly patients. Interact Cardiovasc Thorac Surg 2011;12(5):739-743

10. Suemitsu R, Yamaguchi M, Takeo S, Ondo K, Ueda H et al. Favorable surgical results for patients with nonsmall cell lung cancer over 80 years old: a multicenter survey. Ann Thorac Cardiovasc Surg 2008;14(3):154-160
11. Senbaklavaci O, Taspinar H, Hartert M, Ergun S, Keranen S, Vahl CF. Lobar lung resection in elderly patients with nonsmall cell lung carcinoma: impact of cardiac comorbidity on surgical outcome. Swiss Med Wkly 2012;142:w13742

12. Sekine Y, Suzuki H, Yamada Y, Koh E, Yoshino I. Severity of chronic obstructive pulmonary disease and its relationship to lung cancer prognosis after surgical resection. Thorac Cardiovasc Surg 2013;61(2):124-130

13. Baldi S, Ruffini E, Harari S, Roviaro GC, Nosotti M, Bellaviti N et al. Does lobectomy for lung cancer in patients with chronic obstructive pulmonary disease affect lung function? A multicenter national study. J Thorac Cardiovasc Surg 2005; 130(6):1616-1622

14. Raviv S, Hawkins KA, DeCamp MM, Kalhan R. Lung cancer in chronic obstructive pulmonary disease. Enhancing surgical options and outcomes. Am J Respir Crit Care Med 2011;183(9): 1138-1146

15. Licker MJ, Widikker I, Robert J, Frey J-G, Spiliopoulos A, Ellenberger $\mathrm{C}$ et al. Operative mortality and respiratory complications after lung resection for cancer: impact of chronic obstructive pulmonary disease and time trends. Ann Thorac Surg 2006;81(5):1830-1837

16. Sekine $Y$, Iwata T, Chiyo M, Yasufuku K, Motohashi S, Yoshida $\mathrm{S}$ et al. Minimal alteration of pulmonary function after lobectomy in lung cancer patients with chronic obstructive pulmonary disease. Ann Thorac Surg 2003;76(2):356-361; discussion 362

17. Iwasaki A, Shirakusa T, Enatsu S, Maekawa S, Yoshida Y, Yoshinaga Y. Surgical treatment for lung cancer with COPD based on the Global Initiative for Chronic Obstructive Lung Disease (GOLD). Thorac Cardiovasc Surg 2005;53(3):162-167

18. Sekine $Y$, Behnia $M$, Fujisawa $T$. Impact of COPD on pulmonary complications and on long-term survival of patients undergoing surgery for NSCLC. Lung Cancer 2002; 37(1):95-101

19. Schattenberg T, Muley T, Dienemann H, Pfannschmidt J. Impact on pulmonary function after lobectomy in patients with chronic obstructive pulmonary disease. Thorac Cardiovasc Surg 2007;55(8):500-504

20. Colice GL, Shafazand S, Griffin JP, Keenan R, Bolliger CT. Physiologic evaluation of the patient with lung cancer being considered for resectional surgery: ACCP evidenced-based clinical practice guidelines (2nd edition). Chest 2007;132(3 Suppl):161S-77S

21. Rami-Porta R, Crowley JJ, Goldstraw P. The revised TNM staging system for lung cancer. Ann Thorac Cardiovasc Surg 2009;15(1):4-9

22. Travis WD, Colby TV, Corrin B, Shimosato Y, Brambilla E. In collaboration with Sobin $\mathrm{LH}$ and pathologists from 14 countries. World Health Organization international histological classification of tumours. Histological typing of lung and pleural tumours, 3rd ed. Berlin, Germany: Springer-Verlag, 1999

23. Mathers CD, Loncar D. Projections of global mortality and burden of disease from 2002 to 2030. PLoS Med 2006;3(11):e442 
24. Halbert RJ, Natoli JL, Gano A, Badamgarav E, Buist AS, Mannino DM. Global burden of COPD: systematic review and meta-analysis. Eur Respir J 2006;28(3):523-532

25. World Health Organization. The global burden of disease: 2004 update. Available at: http://www.who.int/healthinfo/ global_burden_disease/2004_report_update/en/index.html. Accessed May 1, 2014.

26. Federal Statistical Office of Germany. Causes of death: The 10 most frequent total causes of death 2012 by the International Statistical Classification of Diseases and Related Health Problems (10th Revision). Available at: https://www.destatis. de/EN/FactsFigures/SocietyState/Health/CausesDeath/ Tables/Deaths/Total.html. Accessed May 1, 2014.

27. Young RP, Hopkins RJ, Christmas T, Black PN, Metcalf $P$, Gamble GD. COPD prevalence is increased in lung cancer, independent of age, sex and smoking history. Eur Respir J 2009; 34(2):380-386

28. Wilson DO, Weissfeld JL, Balkan A, Schragin JG, Fuhrman CR, Fisher SN et al. Association of radiographic emphysema and airflow obstruction with lung cancer. Am J Respir Crit Care Med 2008;178(7):738-744

29. Sherman CB. Health effects of cigarette smoking. Clin Chest Med 1991;12(4):643-658

30. Mayne ST, Buenconsejo J, Janerich DT. Previous lung disease and risk of lung cancer among men and women nonsmokers. Am J Epidemiol 1999;149(1):13-20
31. de Torres JP, Bastarrika G, Wisnivesky JP, Alcaide AB, Campo A, Seijo LM et al. Assessing the relationship between lung cancer risk and emphysema detected on low-dose CT of the chest. Chest 2007;132(6):1932-1938

32. Ekbom A, Helmick C, Zack M, Adami HO. Ulcerative colitis and colorectal cancer: a population-based study. N Engl J Med 1990;323(18):1228-1233

33. Lowenfels AB, Maisonneuve P, Cavallini G, Ammann RW, Lankisch PG, Andersen JR et al. Pancreatitis and the risk of pancreatic cancer. N Engl J Med 1993;328(20):1433-1437

34. Provenzale D, Schmitt C, Wong JB. Barrett's esophagus: a new look at surveillance based on emerging estimates of cancer risk. Am J Gastroenterol 1999;94(8):2043-2053

35. British Thoracic Society; Society of Cardiothoracic Surgeons of Great Britain and Ireland Working Party. BTS guidelines: guidelines on the selection of patients with lung cancer for surgery. Thorax 2001;56(2):89-108

36. Sawada S, Komori E, Nogami N, Bessho A, Segawa Y, Shinkai $\mathrm{T}$ et al. Advanced age is not correlated with either short-term or long-term postoperative results in lung cancer patients in good clinical condition. Chest 2005;128(3):1557-1563

37. Nakajima T, Sekine Y, Yamada Y, Suzuki H, Yasufuku K, Yoshida $\mathrm{S}$ et al. Long-term surgical outcome in patients with lung cancer and coexisting severe COPD. Thorac Cardiovasc Surg 2009;57(6):339-342 